\title{
Solving Fuzzy Transportation Problem using Zero Suffix and Robust Ranking Methodology
}

\author{
M. R. Fegade, V.A. Jadhav ${ }^{1}$, A. A. Muley ${ }^{2}$ \\ 1 Head, Dept. of Statistics, Comp. Sci. and IT, N.E.S. Science College, Nanded. \\ 2 Asst. Prof., Dept. of Statistics, School of Mathematical Sciences, S. R. T. M. University, Nanded.
}

\begin{abstract}
In real world problems, optimization techniques are useful for solving problems like, project schedules, assignment problems and network flow analysis. The main aspect of this paper is to find the least transportation cost of some commodities through a capacitated network when the supply and demand of nodes and the capacity and cost of edges are represented as fuzzy numbers. Here, we are proposed a ranking technique for solving fuzzy transportation problem, where fuzzy demand and supply all are in the form of triangular fuzzy numbers. Here, simple algorithm is proposed for computed fuzzy transportation problem and finally the feasibility of the proposed study is checked with a numerical example.
\end{abstract}

Keywords: - Fuzzy, Transportation Problem, Membership function, Robust Ranking.

\section{INTRODUCTION}

The transportation problem is one of the earliest applications of linear programming problems. The occurrence of randomness and imprecision in the real world is inevitable owing to some unexpected situations. There are cases that the cost coefficients and the supply and demand quantities of a transportation problem may be uncertain due to some uncontrollable factors some of the researchers are studied in[1,3,5,6,7,9]. To deal with imprecise information in making decisions, Zadeh[8] introduced the notion of fuzziness.

A fuzzy transportation problem is a problem in which the transportation cost, supply and demand quantities are fuzzy quantities. The objective of the fuzzy transportation problem is to determine the shipping schedule that minimizes the total fuzzy transportation cost while satisfying fuzzy supply and demand limits.

In this paper, we investigate the transportation problem with fuzzy costs. Since, the objective is to minimize the total cost or to maximize the total profit, subject to some fuzzy constraints, the objective function is also considered as a fuzzy number. The method is to rank the fuzzy objective values of the objective function by some ranking method for numbers to find the best alternative. On the basis of this idea the Robust Ranking method [4] has been adopted a transform the fuzzy transportation problem. The idea is to transform a problem with fuzzy parameters in the form of Linear programming problem and solve it by the Zero Suffix Method[2]. Zadeh [8], first introduced fuzzy set as a mathematical way of representing impreciseness or vagueness in everyday life.

\section{Fuzzy set:}

A fuzzy set is characterized by a membership function mapping element of a domain,Space of the universe of discourse $X$ to the unit interval $[0,1]$ i.e. $A=\{(x, \mu A(x) ; x \in X\}$. Here $\mu A: X \rightarrow[0,1]$ is a mapping called the degree of membership function of the fuzzy set $A$ and $\mu \mathrm{A}(\mathrm{x})$ is called the membership value of $\mathrm{x} \in \mathrm{X}$ in the fuzzy set $\mathrm{A}$. These membership grades are often represented by real numbers ranging from $[0,1]$.

Triangular fuzzy number: $\mu(\mathrm{x})$ given by

For a triangular fuzzy number $\mathrm{A}(\mathrm{x})$, it can be represented by $\mathrm{A}(\mathrm{a}, \mathrm{b}, \mathrm{c} ; 1)$ with membership function

$$
\mu(x)=\left\{\begin{array}{lr}
(x-a) /(x-b) & a \leq x \leq b \\
1 & x=b \\
(c-x) /(c-d) & c \leq x \leq d \\
0 & \text { otherwise }
\end{array}\right.
$$




\subsection{Robust Ranking Technique}

\section{PROPOSED METHODOLOGY}

Robust ranking technique which satisfy compensation, linearity, and additively properties and provides results which are consist human intuition. If $\tilde{a}$ is a fuzzy number then the Robust Ranking is defined by $R(\bar{a})=\int_{0}^{1}(0.5)\left(a_{\alpha}^{L}, a_{\alpha}^{U}\right) d \alpha$, where $\left(a_{\alpha}^{L}, a_{\alpha}^{U}\right)$ is the $\alpha$ level cut of the fuzzy number $\tilde{a}$ In this paper we use this method for ranking the objective values. The Robust ranking index R(ã) gives the representative value of fuzzy number ã.

\subsection{Zero Suffix Method}

We, now introduce a new method called the zero suffix method for finding an optimal solution to the transportation problem.

Step 1: Construct the transportation table.

Step 2: Subtract each row entries of the transportation table from the corresponding row minimum after that subtract each column entries of the transportation table from the corresponding column minimum.

Step 3: In the reduced cost matrix there will be the atleast one zero in each row and column, then find the suffix value of all the zeros in the reduced cost matrix by following simplification, the suffix value is denoted by $\mathrm{S}$,

$$
\text { Therefore } S=\frac{\text { Add the cos } t \text { of nearest adjacent sides of zero which are greater than zero }}{\text { No.of } \cos t s \text { added }}
$$

Step 4: Choose the maximum of $S$, if it has one maximum value then first supply to that demand corresponding to the cell. If it has more equal values then select $\left\{a_{\mathrm{i}}, \mathrm{b}_{\mathrm{j}}\right\}$ and supply to that demand maximum possible.

Step 5: After the above step, the exhausted demands (column) or supplies (row) to be trimmed. The resultant matrix must possess at least one zero is each row and column, else repeat Step 2.

Step 6: Repeat Step 3 to Step 5 until the optimal solution is obtained.

\section{Numerical Example}

The fuzzy transportation cost for unit quantity of the product from $\mathrm{i}^{\text {th }}$ source to $\mathrm{j}^{\text {th }}$ destination is $\mathrm{C}_{\mathrm{ij}}$ where

$$
\left[C_{i j}\right]_{3 \times 4}=\left(\begin{array}{llll}
(-2,3,8) & (-2,3,8) & (-2,3,8) & (-1,1,4) \\
(4,9,16) & (4,8,12) & (2,5,8) & (1,4,7) \\
(2,7,13) & (0,5,10) & (0,5,10) & (4,8,12)
\end{array}\right)
$$

Fuzzy availability of the product at source are $((0,3,6),(2,7,13),(2,5,8))$ and the fuzzy demand of the product at destinations are $((1,4,7),(0,3,5),(1,4,7)(2,4,8))$ respectively.

The fuzzy transportation problems are given table 1 .

Table1

\begin{tabular}{|c|l|l|l|l|l|}
\hline & \multicolumn{1}{|c|}{$\mathrm{D}_{1}$} & \multicolumn{1}{|c|}{$\mathrm{D}_{2}$} & \multicolumn{1}{|c|}{$\mathrm{D}_{3}$} & \multicolumn{1}{|c|}{$\mathrm{D}_{4}$} & Supply \\
\hline $\mathrm{S}_{1}$ & $(-2,3,8)$ & $(-2,3,8)$ & $(-2,3,8)$ & $(-1,1,4)$ & $(0,3,6)$ \\
\hline $\mathrm{S}_{2}$ & $(4,9,16)$ & $(4,8,12)$ & $(2,5,8)$ & $(1,4,7)$ & $(2,7,13)$ \\
\hline $\mathrm{S}_{3}$ & $(2,7,13)$ & $(0,5,10)$ & $(0,5,10)$ & $(4,8,12)$ & $(2,5,8)$ \\
\hline Demand & $(1,4,7)$ & $(0,3,5)$ & $(1,4,7)$ & $(2,4,8)$ & $(4,15,27)$ \\
\hline
\end{tabular}




\section{Solution:}

In Conformation to model the fuzzy transportation problem can be formulated in the following mathematical programming form

Min $Z=R(-2,3,8) \times 11+R(-2,3,8) \times 12+R(-2,3,8) \times 13+R(-1,1,4) \times 14+\mathrm{R}(4,9,16) \times 21+\mathrm{R}(4,8,12) \times 22+$ $\mathrm{R}(2,5,8) \times 23+\mathrm{R}(1,4,7) \times 24+\mathrm{R}(2,7,13) \times 31+\mathrm{R}(0,5,10) \times 32+\mathrm{R}(0,5,10]) \times 33+\mathrm{R}(4,8,12) \times 34$

$R(\bar{a})=\int_{0}^{1}(0.5)\left(a_{\alpha}^{L}, a_{\alpha}^{U}\right) d \alpha$

Where $\left(a_{\alpha}^{L}, a_{\alpha}^{U}\right)=\{(b-a) \alpha+a, c-(c-b) \alpha\}$

$R(-2,3,8)=\int_{0}^{1}(0.5)(5 \alpha-2,8-5 \alpha) d \alpha$

$R(-2,3,8)=\int_{0}^{1}(0.5)(6) d \alpha=3$

Similarly,

$\mathrm{R}(-2,3,8)=3, \quad \mathrm{R}(-2,3,8)=3, \quad \mathrm{R}(-2,3,8)=3, \quad \mathrm{R}(-1,1,4)=1.5, \quad \mathrm{R}(4,9,16)=10, \quad \mathrm{R}(4,8,12)=8 \quad \mathrm{R}(2,5,8)=5$, $\mathrm{R}(1,4,7)=4, \quad \mathrm{R}(2,7,13)=7.5, \mathrm{R}(0,5,10)=5, \quad \mathrm{R}(0,5,10)=5, \mathrm{R}(4,8,12)=8$

Rank of all supply $\mathrm{R}(0,3,6)=3, \mathrm{R}(2,7,13)=7.5, \mathrm{R}(2,5,8)=5$

Rank of all Demands $\mathrm{R}(1,4,7)=4, \mathrm{R}(0,3,5)=2.5, \mathrm{R}(1,4,7)=1.5, \mathrm{R}(2,4,8)=2.5$

By applying the zero suffix method which gives the following allocations in table 2:

Table 2

\begin{tabular}{|c|c|c|c|c|c|}
\hline & $\mathrm{D}_{1}$ & $\mathrm{D}_{2}$ & $\mathrm{D}_{3}$ & $\mathrm{D}_{4}$ & Supply \\
\hline $\mathrm{S}_{1}$ & $\begin{array}{l}3 \\
3\end{array}$ & 3 & 3 & 1.5 & 3 \\
\hline $\mathrm{S}_{2}$ & 10 & 8 & 2.5 & 5 & 7.5 \\
\hline $\mathrm{S}_{3}$ & 7.5 & 2.5 & 1.5 & 8 & 5 \\
\hline Demand & 4 & 2.5 & 4 & 5 & 15.5 \\
\hline
\end{tabular}

Table 3

\begin{tabular}{|c|c|c|c|c|c|}
\hline & $\mathrm{D}_{1}$ & $\mathrm{D}_{2}$ & $\mathrm{D}_{3}$ & $\mathrm{D}_{4}$ & Supply \\
\hline $\mathrm{S}_{1}$ & $\begin{array}{l}\mathbf{( 0 , 3 , 6 )} \\
(-2,3,8)\end{array}$ & $(-2,3,8)$ & $(-2,3,8)$ & $(-1,1,4)$ & $(0,3,6)$ \\
\hline $\mathrm{S}_{2}$ & $(4,9,16)$ & $(4,8,12)$ & $\begin{array}{l}(\mathbf{0 , 3}, \mathbf{3}) \\
\quad(2,5,8)\end{array}$ & $\begin{array}{l}(\mathbf{2 , 4 , 8 )} \\
\quad(1,4,7)\end{array}$ & $(2,7,13)$ \\
\hline $\mathrm{S}_{3}$ & $\begin{array}{l}\mathbf{( 1 , 1 , 1 )} \\
(2,7,13)\end{array}$ & $\begin{array}{l}\mathbf{( 0 , 3 , 5 )} \\
{[0,5,10]}\end{array}$ & $\begin{array}{l}(\mathbf{1}, \mathbf{1}, \mathbf{2}) \\
(0,5,10)\end{array}$ & $(4,8,12)$ & $(2,5,8)$ \\
\hline Demand & $(1,4,7)$ & $(0,3,5)$ & $(1,4,7)$ & $(2,4,8)$ & $(4,15,27)$ \\
\hline
\end{tabular}

In this example, it has been shown that the total optimal cost obtained by our methods remains as that obtained by defuzzifying the total fuzzy optimal cost by applying the Robust's ranking method.

For the fuzzy transportation problem with fuzzy objective function min $z=69$.

\section{Conclusion}

In this paper, the transportation costs are considered as imprecise fuzzy numbers. Here, fuzzy transportation problem has been transformed into crisp transportation problem using Robust ranking method. We can have the optimal solution from crisp and fuzzy optimal total cost of given example. Moreover, Using Robust ranking method one can conclude that the solution of fuzzy problems obtained more effectively. 


\section{REFRENCES}

[1] Fegade M.R., Jadhav V.A., Muley A.A. "Finding an optimal solution of transportation problem using interval and triangular membership functions", European Journal of Scientific Research, Vol.60, No.3

$$
\text { (2011), pp. 415-421. }
$$

[2] Fegade M.R., Jadhav V.A., Muley A.A. "Solution of multi-objective transportation problem using zero suffix and separation method", International eJournal of Mathematics and Engineering, 118 (2011) pp. $1091-1098$.

[3] Liu, Shiang-Tai and Chiang, Kao. "Solving fuzzy transportation problems based on extension principle",European Journal of Operational Research, 153 (2004), pp. 661-674.

[4] Nagarajan R. and Solairaju A. "Computing Improved Fuzzy Optimal Hungarian Assignment Problems with Fuzzy Costs under Robust Ranking Techniques” international journal of computer application, vol 6, No. 4, (2010), pp. 6-13.

[5] Pandian, P. and Natrajan, G. "An optimal More for less solution to fuzzy transportation problem with mixed constraints" Applied mathematical sciences, vol.4, No.29 (2010), pp.1405-1415.

[6] Pandian, P. and Natrajan, G. "A new algorithm for finding a fuzzy optimal solution for fuzzy transportation problem", applied mathematical sciences, vol.4, No.2 (2010), pp.79-90.

[7] Yager R. R. “A procedure for ordering fuzzy subsets of the unit interval”, Information Sciences,24, 143-161 (1981).

[8] Zadeh, L. A."Fuzzy sets, Information and Control”, 8 (1965), pp 338-353.

[9] Zimmermann H.J. “ Fuzzy sets theory and its applications",(1996) Kluwer- Nijhoff,Boston. 